\title{
Subgroup Formation in Teams Working with Robots
}

\author{
Lionel P. Robert Jr. \\ University of Michigan \\ 105 S. State St. \\ Ann Arbor, MI 48109 USA \\ Iprobert@umich.edu \\ Sangseok You \\ University of Michigan \\ 105 S. State St. \\ Ann Arbor, MI 48109 USA \\ sangyou@umich.edu
}

\begin{abstract}
Teams are increasingly adopting robots to accomplish their work. Despite this, more research is needed to understand what makes these teams effective. One such topic not fully explored is the formation of subgroups in teams that work with robots. We conducted a pilot study to explore this topic. The study examined 15 teams of 2 people, each team member working with a robot to accomplish a team task. Results of the pilot study showed that subgroups formed between humans and their robots were negatively correlated with various team outcomes. Although our results are preliminary, we believe our findings can initiate future research on the topic of subgroup formation in teams working with robots.
\end{abstract}

\section{Author Keywords}

Human-robot interaction; human-robot collaboration; teams; subgroups

\section{ACM Classification Keywords}

H.5.2 [User Interfaces and Presentation (e.g., HCI)]: Theory and Methods. H.1.2 [Models and Principles]: User/Machine Systems - human factors. the full citation on the first page. Copyrights for third-party components of this work must be honored. For all other uses, contact the Owner/Author

Copyright is held by the owner/author(s).

CHI'15 Extended Abstracts, Apr 18-23, 2015, Seoul, Republic of Korea.

ACM 978-1-4503-3146-3/15/04.

http://dx.doi.org/10.1145/2702613.2732791

\section{Teams Working with Robots}

The use of robots to support teamwork continues to increase $[1,12,18]$. For example, remote-control robots 
are often paired to work alongside astronauts in space missions [10]. Construction sites and urban searchand-rescue (USAR) teams are employing robots for dangerous and labor-intensive tasks. As a result, robots have become an important fixture in many team settings [20]. Yet, there is much we do not know about what makes these teams effective [18]. The ability to work together as a unit is often lauded as the key to teamwork [17]. The formation of subgroups has the potential to undermine teamwork with robots.

Subgroup formation, the emergence of smaller groups within teams, has been found to undermine teamwork $[15,16]$. Subgroups emerge when relationships among some team members are much stronger than relationships among other team members. The subgroups can essentially divide the team and create discord among team members [3]. These subgroups within teams often compete against one another rather than work together [7]. When this occurs, teams do not operate as cohesive units but instead behave as competing subdivisions. Subgroups have been associated with increases in conflict and decreases in trust, satisfaction and performance in teams $[11,21]$.

Although prior work has not examined the impact of subgroup formation in teams working with robots, research has been done on the impact of attachment between humans and robots. Research has shown that a cohesive relationship between a human and a robot can lead to positive outcomes. For instance, attachment toward one's robot has been associated with greater engagement and enjoyment with the robot $[8,9]$. However, a study of EOD (explosive ordnance disposal) teams using robots suggests that attachment to one's robot may have drawbacks. In these EOD teams attachment to a robot made operators hesitant to deploy the robot during risky situations, and as a result the effectiveness of the EOD decreased [4]. This suggests that attachment between robots and humans is not always desired. Research has not fully explored the potential negative impacts of attachment to one's robot in teams that have the potential for subgroup formation.

Despite the importance of subgroup formation in traditional teams, we know very little about its impact on teamwork involving robots. In this paper, we began to explore the concept of subgroup formation in teams working with robots. Our goal is to determine whether the attachment between individuals and their robot can create a subgroup and have similar negative effects to subgroups in traditional teams. To accomplish this we examined 15 teams working with robots to complete a team task. Results of this study offer preliminary evidence for both the existence and impacts of subgroups in teams working with robots.

\section{Method}

We conducted a pilot study in preparation for a much larger study. The pilot employed a lab experimental design. Thirty individuals were recruited at a large midwestern university in the United States (14 females, mean age 24.7, SD = 7.48). Participants were randomly assigned to a team of two humans and two robots $(N=15)$. Each participant was paired with a robot to accomplish his or her part in the team task. After the task was completed participants answered a questionnaire and were paid $\$ 20$. 


\section{Experimental Task}

The experimental task was to deliver five small (236 $\mathrm{ml}$ ) water bottles from one point to another point using a robot (See Figure 1). The task area was made with cardboard ( 0.44 meters $\times 2.91$ meters). Participants were told that their job as a team was to deliver all five water bottles from point A to point C. Person 1 using robot 1 delivered each water bottle from point $A$ to point $B$. Then, person 2 using robot 2 picked up each water bottle from point $B$ and moved it to point $C$, the final destination. There were four obstacles along the route of each robot. The delivery task was designed to be an interdependent task. For instance, robot 1 was not allowed to be used to deliver water bottles beyond point $B$ and robot 2 could only pick up water bottles from point $B$.

Robot 1 picked up water bottles at

Robot 2 picked up water bottles at Point $A$ and dropped thern at Point

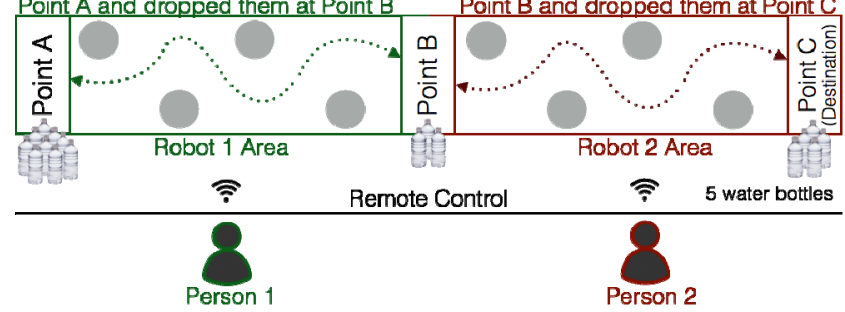

Figure 1. Experimental Task

Robots

The robots used in the experiment were built from LEGO $®$ Mindstorms ${ }^{\circledR}$ EV3 (see Figure 2). The robots were designed to grip plastic water bottles and were controlled by infrared remote controllers. The basic design of the robots was adopted and modified from an example included in the LEGO set.

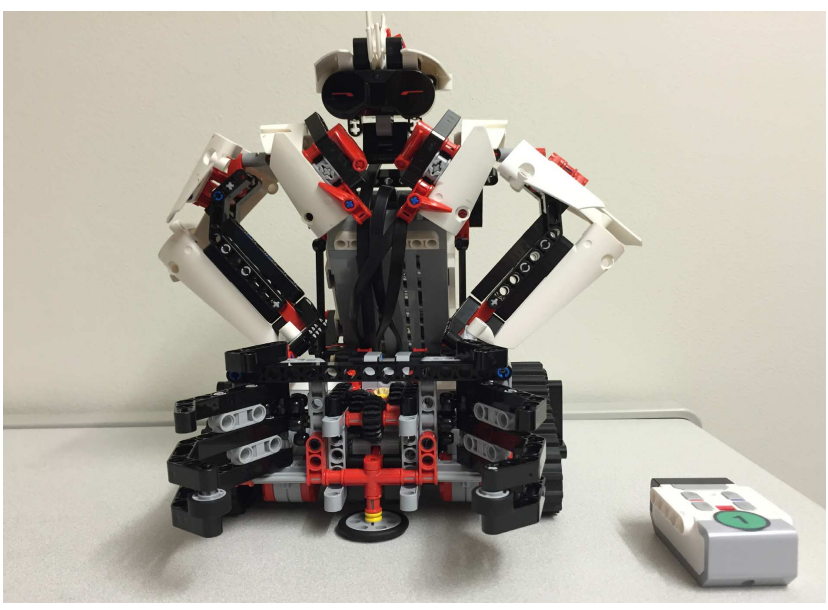

Figure 2. The robot with remote control.

Measures

Three constructs were chosen: team identification, team viability, and perceived team performance. These three constructs were chosen because they have either been shown to predict team performance or used as a proxy of team performance $[3,5,6,7]$. All three constructs were measured using a 5-point Likert scale ranging from 1 for "strongly disagree" to 5 for "strongly agree" and were obtained from individuals and aggregated to the team level. Cronbach's a for all constructs exceeded .90 and all ICCs were above .11.

- Team identification was measured with items adapted from [3]. An example item included "I was happy with being identified as a member of this team." - Team viability was measured using an index of five items adapted from [6]. An example of one item used was "If I had the choice of working in this team including the robots again, I would do it." 


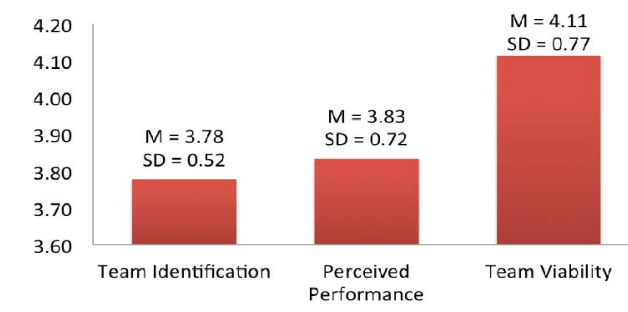

Figure 3. Means and standard deviations of dependent measures
- $\quad$ Perceived performance was measured using an index of three items created for this study. "This team met or exceeded my expectations and fulfilled its overall objectives" was one of the items used.

- Subgroup formation was measured by averaging the level of cohesion reported by participants between themselves and their teammate against their level of cohesion between themselves and their robot. Cohesion was measured using an index of five items adapted from [5]. An example item was "I feel close to this team member." The level of cohesion between participants and their robots was subtracted from the level of cohesion between participants and their teammates. Negative values were coded as a 1 to represent a subgroup while non-negative values were coded as a 0 to represent no subgroup. Because this work was preliminary we were only interested in exploring the possible implications of the existence of subgroups, therefore we dichotomized the construct.

\section{Results}

Means and standard deviations are shown in Figure 3. Because this was a preliminary study we used correlation analysis to determine whether there was a significant relationship between subgroup formation and team identification, viability and perceived performance. We computed Pearson's correlation coefficients (e.g., $r$ ). The correlations between subgroup formation and team identification, viability and perceived performance were $-.68, \mathrm{p}<0.05 ;-.62$, $\mathrm{p}<0.05$, and $-.75, \mathrm{p}<0.01$, respectively.

Results provide evidence that subgroups were formed by strong attachments between humans and their robots. These subgroups were also negatively correlated with important team outcome variables.

\section{Limitations and Future Research}

The study has several limitations. Further research is needed to refine the measurement of subgroup

formation in teams working with robots. For example, there are many measures of subgroup formation; more research is needed to explore which measures are appropriate $[16,21]$. More research is also needed to fully examine the impact of subgroup formation in teams working with robots. The literature has identified many ways subgroup formation can hurt teamwork in traditional teams [2]. In this pilot study we only examined a small set of outcome variables. Future research should investigate what other outcome variables could be impacted by subgroup formation in these teams (e.g., conflict). In addition, our sample size was small and our context was very specific. Additional research could be conducted with larger sample sizes in field settings. Finally, because team size has been shown to impact team outcomes [19], future research should examine size along with subgroup formation.

\section{Implications for Theory and Design}

The existence of subgroups might have broader implications for theory and design of teams and robots for teams. First, research should examine impacts of attachment to robots in larger teams, which have the potential for subgroup formation. Much research has found positive impacts of attachment to robots in dyadic interactions. Yet, our results showed that in teams with more than one human and more than one robot subgroup formation based on one human's attachment to his or her robot was negatively related to various team outcomes. 
Second, our results can inform theory related to subgroup formation in traditional teamwork. Our results demonstrate that subgroup formation can occur when humans are more attached to their robots than teammates. The role of technological artifacts in subgroup formation in traditional teams has not been explored. Yet, technologies such as robots are increasingly playing a more central role in teamwork $[14,18]$. Future research on subgroups in traditional teams should consider examining the role of technologies.

This study also has implications for design. Robots, like other types of technologies [14], can be designed to promote social integration, which is important for teamwork [13]. For designers of robots, this may imply the need to consider ways to alleviate subgroup formation in teams working with robots. For example, in traditional teams without robots, subgroups can be formed by physical appearances related to demographics such as gender, age and ethnicity [11]. To counteract this, robots could be designed to highlight the commonality among all team members, thereby suppressing demographic characteristics that can cause divisions. For example, in mixed-gender teams robots could be designed to be gender-neutral. Another way design could help reduce subgroup formation is by promoting team identification by ensuring that robots include team logos and colors.

\section{Conclusion and Future Research}

Subgroup formation has been shown to be an important element to predicting the effectiveness of teamwork. Despite this, much more work is needed to understand the effects of subgroup formation in teams working with robots. Results of this preliminary study provide some evidence of both the existence and negative impacts of subgroup formation in teams working with robots. It is our hope that this pilot study can begin a conversation about further research on the topic.

\section{References}

[1] Alnuaimi, O., Robert, L., and Maruping, L. Social loafing in brainstorming CMC teams: The role of moral disengagement. System Sciences, 2009. HICSS'09. 42nd Hawaii International Conference on, IEEE (2009), 1-9.

[2] Bezrukova, K., Jehn, K.A., Zanutto, E.L., and Thatcher, S.M. Do workgroup faultlines help or hurt? A moderated model of faultlines, team identification, and group performance. Organization Science 20, 1 (2009), 35-50.

[3] Bos, N.D., Buyuktur, A., Olson, J.S., Olson, G.M., and Voida, A. Shared identity helps partially distributed teams, but distance still matters. Proceedings of the 16th ACM international conference on Supporting group work, ACM (2010), 89-96.

[4] Carpenter, J. The Quiet Professional: An investigation of US military Explosive Ordnance Disposal personnel interactions with everyday field robots. 2013.

https://digital.lib.washington.edu/researchworks/h andle/1773/24197.

[5] Craig, T.Y. and Kelly, J.R. Group cohesiveness and creative performance. Group Dynamics: Theory, Research, and Practice 3, 4 (1999), 243.

[6] Gardner, H.K. and Kwan, L. Expertise Dissensus: $A$ Multi-level Model of Teams' Differing Perceptions about Member Expertise. Harvard Business School Boston, MA, 2012. 
[7] GOYAL, S., MARUPING, L., and ROBERT, L. DIVERSITY AND CONFLICT IN TEAMS: A FAULTLINE MODEL PERSPECTIVE. Academy of Management Proceedings, Academy of Management (2008), 1-6.

[8] Groom, V., Takayama, L., Ochi, P., and Nass, C. I am my robot: the impact of robot-building and robot form on operators. Human-Robot Interaction (HRI), 2009 4th ACM/IEEE International Conference on, IEEE (2009), 31-36.

[9] Hiolle, A., Bard, K.A., and Canamero, L. Assessing human reactions to different robot attachment profiles. Robot and Human Interactive Communication, 2009. RO-MAN 2009. The 18th IEEE International Symposium on, IEEE (2009), 251-256.

[10]Hoffman, G. and Breazeal, C. Collaboration in human-robot teams. Proc. of the AIAA 1st Intelligent Systems Technical Conference, Chicago, IL, USA, (2004).

[11]Li, J. and Hambrick, D.C. Factional groups: A new vantage on demographic faultlines, conflict, and disintegration in work teams. Academy of Management Journal 48, 5 (2005), 794-813.

[12] Munson, S.A., Kervin, K., and Robert Jr, L.P. Monitoring email to indicate project team performance and mutual attraction. Proceedings of the 17th ACM conference on Computer supported cooperative work \& social computing, ACM (2014), 542-549.

[13] Newell, J., Maruping, L., Riemenschneider, C., and Robert, L. Leveraging E-Identities: The Impact of Percieved Diversity on Team Social Integration and Performance. (2008). ICIS 2008 Proceedings, 46.

[14]Newell, J., Robert, L., Riemenschneider, C., and Maruping, L. Influencing Individual Perceptions of
Deep Level Diversity in Virtual Learning Teams (VLT). System Sciences, 2009. HICSS'09. 42nd Hawaii International Conference on, IEEE (2009), $1-10$.

[15]O'Leary, M.B. and Mortensen, M. Go (con) figure: Subgroups, imbalance, and isolates in geographically dispersed teams. Organization Science 21, 1 (2010), 115-131.

[16]Polzer, J.T., Crisp, C.B., Jarvenpaa, S.L., and Kim, J.W. Extending the faultline model to geographically dispersed teams: How colocated subgroups can impair group functioning. Academy of Management Journal 49, 4 (2006), 679-692.

[17] Robert, L.P. A multi-level analysis of the impact of shared leadership in diverse virtual teams. Proceedings of the 2013 conference on Computer supported cooperative work, ACM (2013), 363374.

[18]Robert, L.P. and You, S. Human-Robot Interaction in Groups: Theory, Method, and Design for Robots in Groups. Proceedings of the 18th International Conference on Supporting Group Work, ACM (2014), 310-312.

[19]Srinivasan, S.-S., Maruping, L.M., and Robert, L.P. Idea Generation in Technology-Supported Teams: A Multilevel Motivational Perspective. System Science (HICSS), 2012 45th Hawaii International Conference on, IEEE (2012), 247-256.

[20]Takayama, L., Groom, V., and Nass, C. I'm sorry, Dave: i'm afraid i won't do that: social aspects of human-agent conflict. Proceedings of the SIGCHI Conference on Human Factors in Computing Systems, ACM (2009), 2099-2108.

[21] Thatcher, S. and Patel, P.C. Demographic faultlines: a meta-analysis of the literature. Journal of Applied Psychology 96, 6 (2011), 1119. 